
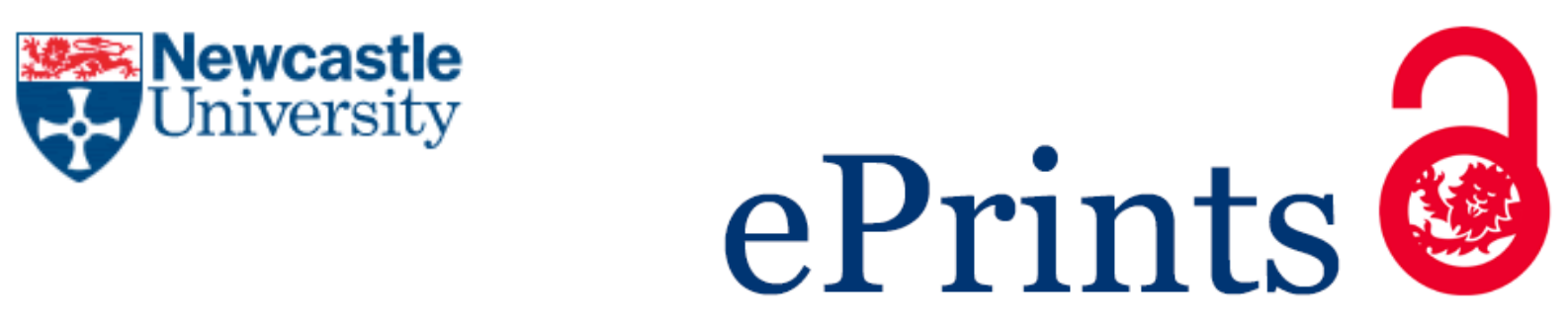
Gonzalez JT, Fuchs CJ, Smith FE, Thelwall PE, Taylor R, Stevenson EJ, Trenell MI, Cermak NM, van Loon LC.

Ingestion of glucose or sucrose prevents liver but not muscle glycogen depletion during prolonged endurance-type exercise in trained cyclists. American Journal of Physiology Endocrinology and Metabolism 2015, 309(12), E1032-E1039

\title{
Copyright:
}

(C) 2015, American Physiological Society. This is the authors accepted manuscript of an article that has been published in its final definitive form by American Physiological Society, 2015.

DOI link to article:

http://dx.doi.org/10.1152/ajpendo.00376.2015

Date deposited:

$22 / 06 / 2016$

Embargo release date:

15 December 2016 
1 Ingestion of Glucose or Sucrose Prevents Liver but not Muscle

2 Glycogen Depletion During Prolonged Endurance-type Exercise in

\section{Trained Cyclists}

4

5 Javier T. Gonzalez ${ }^{1,2}$, Cas J. Fuchs ${ }^{2,3}$, Fiona E. Smith ${ }^{4}$, Pete E. Thelwall ${ }^{4}$, Roy

6 Taylor $^{4}$, Emma J. Stevenson ${ }^{2}$, Michael I. Trenell ${ }^{4}$, Naomi M. Cermak ${ }^{3}$, and

$7 \quad$ Luc J.C. van Loon ${ }^{3}$

8

$9{ }^{1}$ Department for Health, University of Bath, Bath, United Kingdom; '2Faculty of 10 Health and Life Sciences, Northumbria University, Newcastle-upon-Tyne,

11 United Kingdom; '3Department of Human Movement Sciences, NUTRIM

12 School of Nutrition and Translational Research in Metabolism, Maastricht

13 University Medical Centre+ (MUMC+), Maastricht, The Netherlands;

$14{ }^{4}$ Newcastle Magnetic Resonance Centre, Institute of Cellular Medicine, 15 Newcastle University, Newcastle-upon-Tyne, United Kingdom.

16

17 Running head: Carbohydrate ingestion and liver glycogen depletion

19 Corresponding author

20 Luc J.C. van Loon

21 Department of Human Movement Sciences, NUTRIM School of Nutrition and

22 Translational Research in Metabolism, Maastricht University Medical Centre+

23 (MUMC+), Maastricht, The Netherlands.

24 E-mail: I.vanloon@maastrichtuniversity.nl 
ABSTRACT

27 Purpose: To define the effect of glucose ingestion compared to sucrose 28 ingestion on liver and muscle glycogen depletion during prolonged 29 endurance-type exercise. Methods: Fourteen cyclists completed two 3-h 30 bouts of cycling at $50 \%$ of peak power output while ingesting either glucose or 31 sucrose at a rate of $1.7 \mathrm{~g} / \mathrm{min}(102 \mathrm{~g} / \mathrm{h})$. Four cyclists performed an additional

32 third test in which only water was consumed for reference. We employed ${ }^{13} \mathrm{C}$ 33 magnetic resonance spectroscopy to determine liver and muscle glycogen 34 concentrations before and after exercise. Expired breath was sampled during 35 exercise to estimate whole-body substrate use. Results: Following glucose 36 and sucrose ingestion, liver glycogen levels did not show a significant decline 37 following exercise (from $325 \pm 168$ to $345 \pm 205$ and $321 \pm 177$ to $348 \pm 170$ $38 \mathrm{mmol} / \mathrm{L}$, respectively; $P>0.05)$ with no differences between treatments. Muscle 39 glycogen concentrations declined (from $101 \pm 49$ to $60 \pm 34$ and $114 \pm 48$ to $4067 \pm 34 \mathrm{mmol} / \mathrm{L}$, respectively; $P<0.05)$, with no differences between treatments.

41 Whole-body carbohydrate utilization was greater with sucrose $(2.03 \pm 0.43$ $42 \mathrm{~g} / \mathrm{min})$ vs glucose ingestion $(1.66 \pm 0.36 \mathrm{~g} / \mathrm{min} ; P<0.05)$. Both liver (from $43454 \pm 33$ to $283 \pm 82 \mathrm{mmol} / \mathrm{L} ; P<0.05$ ) and muscle (from $111 \pm 46$ to $67 \pm 31$ $44 \mathrm{mmol} / \mathrm{L} ; P<0.01)$ glycogen concentrations declined during exercise when only 45 water was ingested. Conclusion: Both glucose and sucrose ingestion prevent 46 liver glycogen depletion during prolonged endurance-type exercise. Sucrose 47 ingestion does not preserve liver glycogen concentrations more than glucose 48 ingestion. However, sucrose ingestion does increase whole-body 49 carbohydrate utilization compared to glucose ingestion. This trial was 
50 registered at clinicaltrials.gov as NCT02110836. Keywords: glucose; hepatic;

51 metabolism; nutrition; sucrose 


\section{2}

\section{Introduction}

53 Carbohydrate and fat are the main substrates oxidized during moderate-

54 intensity, endurance-type exercise (41). In the fasted state, muscle glycogen

55 and plasma glucose are predominant sources of carbohydrate for oxidation

56 (41), the latter continuously replenished by glycogenolysis and

57 gluconeogenesis from the liver, with smaller contributions from the kidneys 58 and intestine (30). Consequently, in the absence of carbohydrate 59 consumption, liver and muscle glycogen concentrations decrease by $40-60 \%$ 60 within 90 min of exercise at a workload of $70 \%$ of peak oxygen uptake 61 ( $\mathrm{VO}_{2}$ peak $)(6,37)$. Given the importance of liver glycogen for metabolic regulation (16), and the close relationship between liver glycogen content and exercise tolerance (6), it is important to understand the impact of 64 carbohydrate ingestion on liver glycogen depletion during exercise.

65 Carbohydrate feeding during prolonged ( $>2$ h) moderate-to-high intensity, 66 endurance-type exercise enhances endurance performance and capacity 67 (42), attributed to the facilitation of high rates of carbohydrate oxidation, 68 prevention of hypoglycaemia and (under certain conditions) sparing of muscle 69 glycogen $(7,38)$. Though some support has been provided that carbohydrate 70 ingestion can attenuate muscle glycogen depletion $(36,39,40)$, others have 71 failed to confirm these findings $(8,12,15,20)$. Furthermore, prevention of liver 72 glycogen depletion has been suggested $(3,20,21)$, but this has never been 73 experimentally assessed. We speculate that carbohydrate ingestion during 74 exercise attenuates the decline in both liver as well as skeletal muscle 75 glycogen contents. 
77 To maximize carbohydrate availability during exercise, carbohydrate digestion and absorption should be optimized. Previous work suggests that exogenous glucose uptake by the gastrointestinal tract during exercise is restricted to $\sim 1$ $\mathrm{g} / \mathrm{min}(5,17,19)$, attributed to saturation of the sodium-glucose luminal

81 transporter-1 (SGLT-1). However, combined ingestion of glucose and fructose

82 at $\geq 1.8 \mathrm{~g} / \mathrm{min}$ has been shown to result in much higher exogenous 83 carbohydrate oxidation rates (up to $1.75 \mathrm{~g} / \mathrm{min}$ ), compared to the ingestion of 84 equal amount of glucose alone $(17,19)$. The greater uptake and oxidative 85 capacity of glucose and fructose mixtures has been attributed to fructose 86 being absorbed by the glucose transporter-5 (GLUT-5) in the intestine (11). As sucrose (commonly referred to as table sugar) combines glucose and fructose monomers, and sucrose hydrolysis is not rate limiting for intestinal absorption $(14,43)$, we hypothesize that sucrose ingestion at a rate exceeding $1 \mathrm{~g} / \mathrm{min}$ will enhance exogenous carbohydrate availability when

91 compared to the ingestion of an isoenergetic amount of glucose or glucose 92 polymers. Moreover, since fructose appears to be preferentially directed to 93 liver glycogen storage (relative to glucose) (32), sucrose may further prevent 94 liver glycogen depletion during exercise.

96 The present study aimed to investigate the effect of high rates of glucose and sucrose ingestion on net changes in liver and muscle glycogen contents and intramyocellular lipid concentrations using magnetic resonance spectroscopy

99 (MRS). We hypothesized that high-rates of carbohydrate ingestion would 100 spare liver glycogen during prolonged exercise, and that sucrose ingestion 101 would better maintain liver glycogen relative to glucose ingestion. 


\section{Methods}

Study design

105 Participants completed preliminary testing prior to 2 main trials, during which 106 subjects either ingested glucose (GLU) or sucrose (SUC) in a randomized, 107 double-blind, crossover design separated by 7-14 d. Trials were conducted at 108 the Newcastle Magnetic Resonance Centre (Newcastle-upon-Tyne, UK) in

109 accordance with the Second Declaration of Helsinki, and following approval 110 from the Northumbria University Faculty of Health and Life Sciences Ethics

111 Committee. Randomization was performed using online statistical software 112 (http://www.randomizer.org/). Blinding and preparation of the test-drinks was 113 performed by an assistant who was not involved in the exercise tests.

114 In addition to the two main trials, four participants completed an additional 115 control trial $(\mathrm{CON})$ as a reference to establish the change in liver glycogen 116 concentration without carbohydrate ingestion. This was identical to the SUC 117 and GLU trials, with the exception that only water was ingested during 118 exercise (identical volume to GLU and SUC trials), and blood sampling was 119 not performed.

\section{Participants}

122 Fifteen trained cyclists were recruited for the study. Inclusion criteria included

123 healthy, endurance trained, male cyclists; $\dot{\mathrm{V}} \mathrm{O}_{2 \text { peak }} \geq 50 \mathrm{~mL} / \mathrm{min} / \mathrm{kg} /$. Exclusion 124 criteria included the use of medication that could influence substrate 125 metabolism, smokers and any known metabolic disorders. One participant 126 was unable to complete the full $3 \mathrm{~h}$ cycling protocol due to nausea on the GLU 
127 trial and was therefore excluded from the analysis. Consequently, 14 128 participants completed the two main trials.

\section{Preliminary testing}

131 An incremental cycling test was performed on an electromagnetically braked 132 cycle ergometer (Velotron, RacerMate Inc., Seattle, WA, USA) to determine 133 peak power output $\left(W_{\text {peak }}\right)$ and peak oxygen uptake $\left(\mathrm{V}_{2}\right.$ peak $)$. Following a 5134 min warm-up at $100 \mathrm{~W}$, the workload began at $150 \mathrm{~W}$ and was increased by $13550 \mathrm{~W}$ every $2.5 \mathrm{~min}$ to voluntary exhaustion (23). Expired gas was sampled 136 continuously to determine oxygen uptake (Oxycon gas analyser, CareFusion 137 corporation, San Diego, CA, USA).

139 Main trials

140 Participants arrived at Newcastle Magnetic Resonance Centre at 0700-0800 h 141 following a $12 \mathrm{~h}$ fast. Strenuous exercise was prohibited for $24 \mathrm{~h}$ prior to trials, 142 and participants were asked to record and replicate dietary intake for $24 \mathrm{~h}$ 143 prior to trials. The final meal consumed on the evening before the main trials 144 was provided by the investigators to participants to standardize the 145 macronutrient intake across participants for this meal (25 g protein, $51 \mathrm{~g}$ 146 carbohydrate and $32 \mathrm{~g}$ fat; $2479 \mathrm{~kJ} ; 592 \mathrm{kcal})$.

148 MRS was used to determine liver and muscle glycogen and intramyocellular 149 lipid concentrations prior to and following $3 \mathrm{~h}$ of cycling. Following a $5 \mathrm{~min}$ 150 warm-up at $100 \mathrm{~W}$, power output was increased to $50 \% W_{\text {peak }}$ for the

151 remainder of the $3 \mathrm{~h}$. Immediately prior to exercise, participants were provided 
152 with $600 \mathrm{~mL}$ (86.4 $\mathrm{g}$ carbohydrate) of the test-drink, and then a further $150 \mathrm{~mL}$

153 (21.6 g carbohydrate) every 15 min during exercise. Four of the 14 cyclists did 154 not manage to consume all of the carbohydrate on their first trial (which was a 155 GLU trial for two participants, and a SUC trial for the other two participants) 156 and therefore their carbohydrate intake was replicated for their second trial 157 (the carbohydrate intakes for these four cyclists therefore ranged from 238$158281 \mathrm{~g}$, mean \pm SD: $292 \pm 101 \mathrm{~g}$, compared to the $324 \mathrm{~g}$ prescribed). This lead 159 to an average rate of carbohydrate intake for the entire group of $1.7 \pm 0.2$ $160 \mathrm{~g} / \mathrm{min}$ and $1.7 \pm 0.2 \mathrm{~g} / \mathrm{min}(102 \pm 12 \mathrm{~g} / \mathrm{h}$ and $102 \pm 12 \mathrm{~g} / \mathrm{h})$ during $\mathrm{GLU}$ and 161 SUC trials, respectively $(P>0.05$; Table 1$)$.

162

163 Carbohydrate drinks

164 Carbohydrate drinks were prepared by mixing $108 \mathrm{~g}$ of carbohydrate with 750 $165 \mathrm{~mL}$ of water in an opaque bottle. This was replicated two more times to 166 produce 3 bottles, each with $750 \mathrm{ml}$ of a $7 \%$ carbohydrate solution; $324 \mathrm{~g}$ of 167 carbohydrate in total. Both sources of carbohydrate were from plants that use $168 \mathrm{C}_{3}$ carbon fixation to minimize differences in the natural abundance of ${ }^{13} \mathrm{C}$ 169 (33). Accordingly, the glucose drink was produced with dextrose monohydrate 170 obtained from wheat (Roquette, France) and the sucrose drink was produced 171 with granulated sugar beet (AB Sugar, UK).

173 Blood sampling and analysis

174 Prior to exercise, an intravenous catheter was inserted into an antecubital 175 vein for regular sampling. Blood samples were obtained prior to the exercise 176 bout, and every 30 min during exercise. Briefly, $10 \mathrm{~mL}$ of blood was collected 
177 in EDTA-vacutainers and immediately centrifuged at $2000 \mathrm{~g}$ for $10 \mathrm{~min}$ at $4^{\circ} \mathrm{C}$.

178 Plasma was then aliquoted and stored at $-80^{\circ} \mathrm{C}$ for subsequent determination

179 of insulin (IBL International, Hamburg, Germany) and non-esterified fatty acid 180 (NEFA) concentrations (WAKO Diagnostics, Richmond, VA) in duplicate 181 (intra- and inter-assay coefficients of variation all $<10 \%$ ). An additional $20 \mu \mathrm{L}$ 182 of whole blood was collected in a capillary tube and was used to determine 183 glucose and lactate concentrations immediately (Biosen C_line, EKF 184 Diagnostics, Magdeberg, Germany).

186 Expired gas analysis

187 Expired breath samples were taken every 30 min throughout exercise using 188 the Douglas bag technique (9) accounting for variance in ambient oxygen and 189 carbon dioxide concentrations (1). A mouthpiece connected to a two-way, 190 non-rebreathing valve (model 2730, Hans Rudolph, Kansas City, Missouri), 191 was used to collect gas samples (60 s sample after a 60 s stabilization 192 phase), analysed for concentrations of oxygen and carbon dioxide using a 193 paramagnetic and infrared transducers, respectively (Servomex 5200S, 194 Crowborough, East Sussex, UK). Sensors were turned on 60 min prior to a 195 two-point calibration (zero: 100\% nitrogen; span: $20 \%$ oxygen and 8\% carbon 196 dioxide) using accuracy certified gas standards (BOC Industrial Gases, Linde 197 AG, Munich, Germany).

199 Ambient temperature, humidity and barometric pressure using a Fortin 200 barometer (F.D. and company, Watford, UK) were recorded, and expired gas 201 samples were corrected to standard temperature and pressure (dry). Volume 
and temperature of expired gas samples were determined using a dry gas

203 meter (Harvard Apparatus, Edenbridge, Kent, UK) and thermistor (model 810-

204 080, ETI, Worthing, UK), respectively, during gas evacuation. Calibration of

205 the dry gas meter was performed regularly with a 3-L syringe (Series 5530,

206 Hans-Rudolph Inc, Kansas City, Missouri, USA).

207

208 Subjective ratings

209 Ratings of gut discomfort were assessed every 30 min during exercise using a

210 5-point scale, where 1 was anchored at "no discomfort' and 5 at "maximum

211 discomfort". Ratings of perceived exertion (RPE) were assessed using the

212 Borg scale (2).

213

214 Measurement of muscle and liver glycogen

215 Tissue glycogen concentration was determined from the magnitude of the

216 natural abundance signal from the C-1 carbon of glycogen at a frequency of

217100.3 ppm. A Philips 3 Tesla Achieva scanner (Philips Healthcare, Best, The

218 Netherlands) was used with a $6 \mathrm{~cm}$ diameter ${ }^{13} \mathrm{C}$ surface coil with integral ${ }^{1} \mathrm{H}$

219 decoupling surface coil (PulseTeq, Worton under Edge, UK) to measure

220 muscle glycogen concentration and an in-house built $12 \mathrm{~cm}{ }^{13} \mathrm{C} /{ }^{1} \mathrm{H}$ surface

221 coil used to measure liver glycogen concentration.

222

223 For muscle glycogen measurements, the surface coil was placed over the

224 widest part of the Vastus lateralis and the leg was held in position with fabric

225 straps to prevent movement. Pulse power was calibrated to a nominal value

226 of $80^{\circ}$ by observing the power dependent variation in signal from a fiducial 
marker located in the coil housing, containing a sample exhibiting ${ }^{13} \mathrm{C}$ signal

228 with short $\mathrm{T}_{1}\left(213 \mathrm{mM}\left[2-{ }^{13} \mathrm{C}\right]\right.$-acetone and $25 \mathrm{mM} \mathrm{GdCl} 3$ in water). Automated

229 shimming was carried out to ensure that the magnetic field within the scanner

230 was uniform over the active volume of the ${ }^{13} \mathrm{C}$ coil. The ${ }^{13} \mathrm{C}$ spectra were

231 acquired over 15 min using a non-localized ${ }^{1} \mathrm{H}$ decoupled ${ }^{13} \mathrm{C}$ pulse-acquire

232 sequence (TR $120 \mathrm{~ms}$, spectral width $8 \mathrm{kHz}, 7000$ averages, WALTZ

233 decoupling). ${ }^{1} \mathrm{H}$ decoupling was applied for $60 \%$ of the ${ }^{13} \mathrm{C}$ signal acquisition

234 to allow a relatively fast TR of $120 \mathrm{~ms}$ to be used within the Specific 235 Absorption Rate safety limitations.

236

237 For liver glycogen measurements the ${ }^{13} \mathrm{C} /{ }^{1} \mathrm{H}$ surface coil was placed over the 238 right lobe of the liver. Spectra were acquired over 15 min using non-localized

$239{ }^{1} \mathrm{H}$ decoupled ${ }^{13} \mathrm{C}$ pulse acquisition sequences (TR $300 \mathrm{~ms}$, spectral width 8 $240 \mathrm{kHz}, 2504$ averages, WALTZ decoupling, nominal ${ }^{13} \mathrm{C}$ tip angle of $\left.80^{\circ}\right)$. Scout 241 images were obtained at the start of each study to confirm optimal coil 242 position relative to the liver.

244 Tissue glycogen concentrations were calculated from the amplitude of the C1245 glycogen ${ }^{13} \mathrm{C}$ signal using Java Based Magnetic Resonance User Interface 246 (jMRUI) version 3.0 and the AMARES algorithm [7] as described in detail 247 previously $(25,26,28,37)$.

249 Measurement of intramyocellular lipid

250 Intramyocellular lipid content was determined routinely, as described in more 251 detail previously (37). In short, a $12 \mathrm{~cm}{ }^{1} \mathrm{H}$ transmitter/receiver coil was used 
252 to obtain ${ }^{1} \mathrm{H}$ spectra to measure intramyocellular lipid (IMCL) content in the 253 widest part of the gastrocnemius. The PRESS (Point Resolved Spectroscopy)

254 (4) sequence was used to acquire ${ }^{1} \mathrm{H}$ spectra from a $2 \times 2 \times 2 \mathrm{~cm}$ voxel, using 255 an echo time of $25 \mathrm{~ms}$, spectral resolution of $1 \mathrm{~Hz}$ and repetition time of 5000 256 ms with 32 acquisitions. Spectra were analyzed with JMRUI version 3.0 using 257 the least square fitting AMARES algorithm $(4,31)$. The inter-observer bias 258 was $0.09 \mathrm{mmol} / \mathrm{L}$ with a $95 \%$ limit of agreement of $0.8 \mathrm{mmol} / \mathrm{L}(P>0.05)$.

\section{Calculations and statistical analysis}

261 Due to the lack of data regarding exercise-induced changes in liver glycogen 262 concentrations with carbohydrate feeding, a sample size estimation was 263 based on data from exogenous carbohydrate oxidation rates (as a surrogate 264 for carbohydrate availability). Sucrose increases exogenous carbohydrate 265 oxidation during cycling by $\sim 30 \%$ (18). Using this figure, along with the $7 \%$ 266 intra-individual coefficient of variation of hepatic glycogen content measured 267 by ${ }^{13} \mathrm{C}$ MRS (34), the study was designed to provide statistical power above $26890 \%$ with an alpha level of 0.05 with a minimum sample size of $n=7$ in a 269 crossover design (10).

271 Whole-body rates of carbohydrate and lipid utilization were estimated using 272 the following equations assuming negligible protein oxidation $(13,22)$ : 
277 Units of $\dot{\mathrm{VO}}{ }_{2}$ and $\dot{\mathrm{V}} \mathrm{CO}_{2}$ are $\mathrm{L} / \mathrm{min}$

279 Unless otherwise stated, all data were expressed in the text as the mean \pm 280 standard deviation (SD) of the mean and the error bars presented in figures 281 are 95\% confidence intervals $(\mathrm{Cl})$. Data were checked for normal distribution 282 and log-transformed if appropriate prior to statistical analysis.

284 Liver and muscle glycogen, and IMCL concentrations from the four 285 participants who completed the CON trial were assessed by two-way (trial $\mathrm{x}$ 286 time) repeated measures ANOVA with trial (GLU vs SUC vs CON) and time 287 (pre- vs post-exercise) as within-subject factors. Rates of substrate utilization were assessed by a one-way repeated measures (GLU vs SUC vs CON) ANOVA. No further inferential statistics were performed on CON data since 290 this was only a subgroup of the total sample and was only used as a 291 reference for the change in liver glycogen concentration with $3 \mathrm{~h}$ of exercise in 292 the absence of carbohydrate ingestion. Accordingly, all other comparisons 293 were made between GLU and SUC only.

295 Blood, plasma and respiratory variables and subjective ratings were assessed 296 by two-way (trial $x$ time) repeated measures ANOVA with trial (GLU vs SUC) 297 and time (all time points during exercise) as within-subject factors. Liver and 298 muscle glycogen and intramyocellular lipid concentrations were also assessed 299 by two-way (trial $x$ time) repeated measures ANOVA with trial (GLU vs SUC) 
300 and time (pre- vs post-exercise) as within-subject factors. Mean exercise 301 responses in GLU and SUC trials (carbohydrate intake, heart rate, fluid intake 302 and power output) were assessed by paired t-tests. All $P$ values are corrected 303 for multiple comparisons (Holm-Sidak). A $P$ value of $\leq 0.05$ was used to 304 determine statistical significance. All data were analyzed using Prism v5 305 (GraphPad Software, San Diego, CA). 


\section{Results}

Participants

309 Participants' characteristics are provided in Table 2. No differences were

310 observed for age, body mass, height, $\dot{\mathrm{V}} \mathrm{O}_{2}$ peak, $W_{\text {peak, }}$ body mass index,

311 systolic or diastolic blood pressure between participants who completed the 312 main trials (GLU and SUC) and the subgroup of participants who also 313 completed the additional CON trial.

\section{Subjective ratings}

316 RPE increased during exercise (time effect, $P<0.001$ ), but to less of an 317 extent during SUC when compared to GLU (interaction effect, $P<0.05$;

318 Figure 1A), becoming significantly different between trials from 150 min 319 onwards $(P<0.05)$. Similarly, ratings of gut discomfort increased throughout 320 exercise (time effect, $P<0.001$ ) but to less of an extent during SUC when 321 compared to GLU (interaction effect, $P<0.01$ ), becoming significantly 322 different at $180 \mathrm{~min}$ (Figure $1 \mathrm{~B}, P<0.05)$.

324 Respiratory data and whole-body substrate utilization

$325 \dot{\mathrm{VO}_{2}}$ and $\dot{\mathrm{V}} \mathrm{CO}_{2}$ remained stable during exercise (time effect, $P>0.05$ for 326 both) and were not different between GLU and SUC (both $P>0.05$ ). 327 Respiratory exchange ratio (RER) was higher with SUC vs GLU (trial effect, $P$ $328<05)$ for time points 90 min onwards (interaction effect, $P<0.05$; Figure 2C). 329 Whole-body carbohydrate utilization rates were higher during SUC (2.03 \pm $3300.43 \mathrm{~g} / \mathrm{min})$ when compared with GLU $(1.66 \pm 0.36 \mathrm{~g} / \mathrm{min} ; P<0.05)$, at the 
331 expense of fat oxidation rates (SUC: $0.35 \pm 0.15$ vs GLU: $0.48 \pm 0.12 \mathrm{~g} / \mathrm{min}$; $P$

$332<0.05)$, resulting in energy expenditure rates that did not differ between trials

333 (SUC: $8.8 \pm 1.2$ vs GLU: $8.6 \pm 0.9 \mathrm{MJ}$; $P>0.05$; Figure $3 \mathrm{~A}$ ). In the subgroup

334 who also completed the CON trial $(n=4)$, whole-body fat oxidation rates were

335 lower during both GLU $(0.42 \pm 0.10 \mathrm{~g} / \mathrm{min})$ and SUC $(0.33 \pm 0.11 \mathrm{~g} / \mathrm{min})$, 336 compared to $\operatorname{CON}(0.64 \pm 0.19$ g.min; $P<0.05)$, whilst carbohydrate oxidation 337 rates (SUC: $2.04 \pm 0.40$ vs GLU: $1.79 \pm 0.43$ vs CON: $1.20 \pm 0.44 \mathrm{MJ}$ ) did not 338 significantly differ between trials $(P>0.05)$. Accordingly, energy expenditure 339 (SUC: $8.7 \pm 0.6$ vs GLU: $8.6 \pm 0.8$ vs CON: $8.4 \pm 0.4 \mathrm{MJ}$ ) also did not differ 340 between trials $(P>0.05$; Figure 3B).

Circulating metabolite and insulin concentrations

343 Blood glucose and plasma insulin concentrations were not significantly 344 different between trials (trial effect, $P>0.05$; interaction effect, $P>0.05$ for 345 both variables; Figure 4A). In contrast, blood lactate concentrations were 346 higher with SUC vs GLU (trial effect, $P<0.01$ ), rising at the onset of exercise 347 (time effect, $P<0.001$ ) to a greater extent in SUC vs GLU until $120 \mathrm{~min}$ 348 (interaction effect, $P<0.01$; Figure 4B). Plasma NEFA concentrations fell 349 from $\sim 0.5 \mathrm{mmol} / \mathrm{L}$ to $\sim 0.2 \mathrm{mmol} / \mathrm{L}$ during the first hour of exercise before rising 350 again (time effect, $P<0.001$ ), the latter of which occurred to a greater degree 351 in GLU compared to SUC (interaction effect, $P<0.01$; Figure 4D).

353 Muscle and liver glycogen concentration

354 Muscle and liver glycogen concentrations are displayed in Figures 5A, 5B, $3555 \mathrm{C}$ and 5D. Pre-exercise, no differences were observed in liver and muscle 
356 glycogen concentrations between trials $P>0.05$ for both variables). The day-

357 to-day coefficients of variation for pre-exercise liver and muscle glycogen

358 concentrations were $12 \%$ and $20 \%$, respectively. The between subject

359 coefficient of variation for pre-exercise liver and muscle glycogen were $54 \%$

360 and $41 \%$, respectively. In the subgroup who also completed the CON trial ( $n=$

361 4), liver glycogen concentrations declined during exercise in CON, but not

362 when either glucose or sucrose were ingested (interaction effect, $P<0.05$;

363 Figure 5B). In contrast to the liver, muscle glycogen concentrations declined

364 during exercise regardless of trial (trial effect, $P>0.05$; time effect, $P<0.01$;

365 interaction effect, $P>0.05$; Figure 5D).

366

367 Post-exercise liver glycogen concentrations did not differ from pre-exercise

368 values when either glucose or sucrose were ingested (time effect, $P>0.05$;

369 interaction effect, $P>0.05)$. The change in liver glycogen concentrations from

370 pre- to post-exercise was positive with glucose (20 $\pm 55 \mathrm{mmol} / \mathrm{L})$ and sucrose

371 (27 $\pm 58 \mathrm{mmol} / \mathrm{L} ; P>0.05 \mathrm{GLU}$ vs SUC) ingestion, but negative in the CON 372 treatment $(-171 \pm 73 \mathrm{mmol} / \mathrm{L})$.

373

374 Muscle glycogen concentrations were reduced following exercise (time effect,

$375 P<0.001)$. The changes in muscle glycogen concentrations did not differ

376 between trials (trial effect, $P>0.05$; interaction effect, $P>0.05$; Figures $5 \mathrm{C}$

377 and 4D). The pre- to post-exercise changes in muscle glycogen concentration

378 did not differ between GLU $(-40 \pm 37 \mathrm{mmol} / \mathrm{L})$ and SUC $(-47 \pm 36 ; P>0.05)$.

380 Intramyocellular lipid concentration 
381 No differences were observed in pre-exercise IMCL concentration $(P>0.05)$

382 between trials. The day-to-day coefficient of variation for pre-exercise IMCL

383 concentration was $21 \%$. The between-subject coefficient of variation for pre-

384 exercise IMCL concentration was $47 \%$. In the full sample $(n=14)$ exercise

385 decreased IMCL concentrations (time effect $P<0.01$ ) to a similar extent in

386 both trials (trial effect, $P>0.05$; interaction effect, $P>0.05$; Figure 5E). The

387 pre- to post-exercise changes in IMCL concentration did not differ between

388 GLU $(-1.5 \pm 6.0 \mu \mathrm{mol} / \mathrm{g})$ and SUC $(-1.6 \pm 6.4 \mu \mathrm{mol} / \mathrm{g} ; P>0.05)$.

389

390 In the subgroup who completed the CON trial $(n=4)$, post-exercise IMCL

391 concentrations were not significantly different to pre-exercise values (time

392 effect, $P>0.05$ ), and the responses were not significantly different between

393 trials (trial effect, $P>0.05$; interaction effect, $P>0.05$; Figure 5F). 


\section{Discussion}

395 In the present study we provide novel data demonstrating that carbohydrate 396 ingestion during endurance type exercise can prevent liver glycogen 397 depletion, and that this effect is independent of the type of carbohydrate 398 (glucose or sucrose) ingested. In contrast, neither glucose nor sucrose 399 ingestion at $1.7 \mathrm{~g} / \mathrm{min}(102 \mathrm{~g} / \mathrm{h})$ could attenuate the decline in muscle 400 glycogen following exercise. Sucrose ingestion increased whole-body 401 carbohydrate utilization when compared with glucose ingestion.

402

403 Muscle glycogen and plasma glucose are the main fuel sources during 404 prolonged, moderate-intensity endurance type exercise (41). Plasma glucose 405 is maintained during exercise by glycogenolysis and gluconeogenesis, 406 primarily from the liver. Accordingly, continuous exercise lasting more than 60 407 min substantially depletes liver glycogen concentrations (37). Given that liver 408 glycogen strongly associates with endurance capacity (6), maintaining liver 409 glycogen concentrations is likely to benefit endurance performance. Previous 410 research using glucose tracers has indicated that high rates of glucose 411 ingestion can suppress endogenous glucose appearance (21), implying that 412 carbohydrate ingestion during exercise may attenuate exercise induced liver 413 glycogen depletion. Here we present the first quantitative evidence of liver 414 glycogen maintenance following carbohydrate ingestion during exercise. We 415 found that $3 \mathrm{~h}$ of cycling, in the absence of carbohydrate ingestion reduces 416 liver glycogen concentrations by $\sim 49 \%$, which is consistent with previous 417 findings (37). When ingesting $\sim 1.7 \mathrm{~g} / \mathrm{min}(\sim 102 \mathrm{~g} / \mathrm{h})$ glucose or sucrose, liver 
glycogen concentrations are not lowered during prolonged exercise (Figures

$4195 \mathrm{~A}$ and 5B).

421 Liver glycogen concentrations displayed a relatively high variability between 422 subjects (coefficient of variation: 54\%), compared to the day-to-day variability 423 within subjects (coefficient of variation: 12\%). This provides an explanation for 424 the relatively higher baseline liver glycogen concentrations in the subgroup 425 that completed the CON trial ( $n=4$; Figure 5B) compared to the entire sample $426(n=14 ;$ Figure 5A).

428 Carbohydrate ingestion during exercise increases exogenous carbohydrate 429 oxidation and has been shown to spare net muscle glycogen utilization under 430 some conditions (36), although not typically during the latter stages of more 431 prolonged (> $1 \mathrm{~h}$ ), cycling exercise. These responses are thought to contribute 432 to the performance benefits of carbohydrate ingestion during prolonged 433 exercise (7). The present data demonstrate that neither the ingestion of 434 glucose nor sucrose are able to attenuate net muscle glycogen utilization 435 during prolonged moderate-intensity cycling, even when large quantities of 436 multiple transportable carbohydrate $(\sim 1.7 \mathrm{~g} / \mathrm{min} ; 102 \mathrm{~g} / \mathrm{h})$ are ingested that 437 augment exogenous carbohydrate availability. In contrast, whole body 438 carbohydrate utilization rates were higher with sucrose vs glucose ingestion, 439 with a concomitant reduction in fat use. Data from the subgroup also 440 demonstrate that both glucose and sucrose ingestion suppress fat utilization 441 relative to $\mathrm{CON}$, although the numerical differences in carbohydrate utilization 442 rates did not reach statistical significance with the subgroup ( $n=4 ; P=0.07$ ). 
443 At rest, fructose is preferentially stored as liver glycogen rather than muscle

444 glycogen. This has led some to speculate that sucrose, when compared with

445 glucose ingestion may be particularly effective at maintaining or increasing

446 liver glycogen during exercise. In the present study, sucrose ingestion did not

447 preserve liver glycogen concentrations to any greater extent than glucose

448 ingestion. In line with previous observations of substantial declines in

449 endogenous glucose production during exercise when glucose was ingested

450 (21), our data seem to suggest that liver glycogen contents are maintained

451 during exercise when ingesting large amounts $(\sim 1.7 \mathrm{~g} / \mathrm{min} ; \sim 102 \mathrm{~g} / \mathrm{h})$ of

452 glucose or sucrose. The surplus carbohydrates are shunted towards oxidation

453 rather than storage, at the expense of lipid oxidation.

454

455 The increase in whole-body carbohydrate utilization following sucrose vs

456 glucose ingestion seems to confirm that sucrose ingestion increases

457 exogenous carbohydrate availability and carbohydrate flux. This shift in

458 metabolism is likely due to a number of coordinated factors, including the

459 higher lactate concentrations observed following sucrose ingestion. Higher

460 circulating lactate concentrations are very likely due to the fructose

461 component of sucrose, the majority of which is converted to lactate and

462 glucose upon bypassing the liver. Glucose-fructose co-ingestion during

463 exercise has been shown to increase plasma lactate and glucose turnover

464 and oxidation (24), with a minimal amount of fructose being directly oxidized

465 (24). The greater whole-body carbohydrate utilization rate following sucrose

466 ingestion is therefore likely attributed to a combination of (greater) plasma

467 lactate, glucose and (to a lesser extent) fructose oxidation rates. Lactate also 
468 inhibits adipocyte lipolysis via the G-protein coupled receptor GPR81 (27).

469 This is likely one of the factors responsible for the lower plasma NEFA

470 concentrations following sucrose versus glucose ingestion in the presence of

471 similar insulinemia. As there were no differences in muscle lipid content

472 changes between treatments, the greater fat use in the glucose compared

473 with the sucrose trial is likely entirely attributed to greater uptake and

474 oxidation of plasma derived NEFA.

475

476 Lactate formation is associated with hydrogen ion production, which may 477 displace $\mathrm{CO}_{2}$ from bicarbonate stores with consequent implications for 478 estimates of $\dot{\mathrm{V}} \mathrm{CO}_{2}, \mathrm{RER}$ and substrate utilization (13). The $\sim 0.5 \mathrm{mmol} / \mathrm{L}$ 479 increase in lactate concentration following SUC vs GLU however, would have 480 a negligible $(<0.07 \mathrm{~mL} / \mathrm{min})$ effect on $\mathrm{CO}_{2}$ displacement (13). Therefore, 481 values obtained from expiratory gas samples are likely to be a valid 482 representation of net substrate utilization.

484 We observed a lower RPE towards the end of exercise following sucrose 485 compared with glucose ingestion. This is in spite of the higher lactate 486 concentrations following ingestion of sucrose compared to glucose, offering 487 additional evidence of the disassociation between lactate concentrations and 488 RPE (29). Exogenous carbohydrate oxidation rates have been shown to 489 correlate with exercise performance during prolonged, moderate-to-high 490 intensity exercise (35). Therefore, the lower RPE following sucrose versus 491 glucose ingestion may be attributed to the greater exogenous carbohydrate 492 uptake and subsequent oxidation rates when co-ingesting fructose $(17,19)$. 
493 The lower RPE may of course also be directly attributed to the lesser 494 occurrence of gastrointestinal discomfort when ingesting large amounts of 495 multiple transportable carbohydrates versus glucose only (Figure 1).

496

497 In conclusion, ingestion of large amounts $[\sim 1.7 \mathrm{~g} / \mathrm{min}(\sim 102 \mathrm{~g} / \mathrm{h})$, relative to 498 the $\sim 1.5 \mathrm{~g} / \mathrm{min}(90 \mathrm{~g} / \mathrm{h})$ recommended for exercise lasting $>2.5 \mathrm{~h}$ ] of glucose 499 or sucrose during prolonged endurance type exercise prevent the exercise500 induced decline in liver glycogen content without modulating muscle glycogen 501 depletion. 


\section{Acknowledgements}

503 The authors wish to thank the volunteers for their time and effort in 504 participating in this study. We also thank R Veasey and $\mathrm{J}$ Forster for blinding 505 and test-drink preparation, and Louise Ward, Dorothy Wallace and Tim 506 Hodgson for assistance with magnetic resonance examinations. Professor 507 Trenell is supported by a Senior Fellowship from the National Institute for 508 Health Research.

509

510 Disclosures

511 This study was funded by Sugar Nutrition UK and Suikerstichting Nederland. 
513 1. Betts JA, and Thompson D. Thinking outside the bag (not necessarily 514 outside the lab). Med Sci Sports Exerc 44: 2040; author reply 2041, 2012.

5152 2. Borg GA. Perceived exertion: a note on "history" and methods. Med 516 Sci Sports 5: 90-93, 1973.

517 3. Bosch AN, Dennis SC, and Noakes TD. Influence of carbohydrate 518 ingestion on fuel substrate turnover and oxidation during prolonged exercise. $519 J$ J Appl Physiol (1985) 76: 2364-2372, 1994.

520 4. Bottomley PA. Spatial localization in NMR spectroscopy in vivo. Ann $521 \quad$ New York Acad Sci 508: 333-348, 1987.

$522 \quad 5 . \quad$ Burke LM, Hawley JA, Wong SH, and Jeukendrup AE.

523 Carbohydrates for training and competition. J Sports Sci 29 Suppl 1: S17-27, 5242011.

525 6. Casey A, Mann R, Banister K, Fox J, Morris PG, Macdonald IA, and 526 Greenhaff PL. Effect of carbohydrate ingestion on glycogen resynthesis in 527 human liver and skeletal muscle, measured by (13)C MRS. Am J Physiol 528 Endocrinol Metab 278: E65-75, 2000.

$5297 . \quad$ Cermak NM, and van Loon LJ. The use of carbohydrates during 530 exercise as an ergogenic aid. Sports Med 43: 1139-1155, 2013.

531 8. Coyle EF, Coggan AR, Hemmert MK, and Ivy JL. Muscle glycogen utilization during prolonged strenuous exercise when fed carbohydrate. $J$ Appl Physiol 61: 165-172, 1986.

9. Douglas CG. A method for determining the total respiratory exchange in man. J Physiol 42: xvii-xviii, 1911.

10. Faul F, Erdfelder E, Lang AG, and Buchner A. G*Power 3: a flexible statistical power analysis program for the social, behavioral, and biomedical sciences. Beh Res Methods 39: 175-191, 2007.

11. Ferraris RP, and Diamond J. Regulation of intestinal sugar transport. Physiol Rev 77: 257-302, 1997.

12. Flynn MG, Costill DL, Hawley JA, Fink WJ, Neufer PD, Fielding RA, and Sleeper MD. Influence of selected carbohydrate drinks on cycling performance and glycogen use. Med Sci Sports Exerc 19: 37-40, 1987. 13. Frayn KN. Calculation of substrate oxidation rates in vivo from gaseous exchange. J Appl Physiol 55: 628-634, 1983.

14. Gray GM, and Ingelfinger FJ. Intestinal absorption of sucrose in man: interrelation of hydrolysis and monosaccharide product absorption. J Clin Invest 45: 388-398, 1966.

15. Hargreaves $\mathbf{M}$, and Briggs $\mathbf{C A}$. Effect of carbohydrate ingestion on exercise metabolism. J Appl Physiol 65: 1553-1555, 1988.

16. Izumida Y, Yahagi N, Takeuchi Y, Nishi M, Shikama A, Takarada A, Masuda Y, Kubota M, Matsuzaka T, Nakagawa Y, lizuka Y, Itaka K, Kataoka K, Shioda S, Niijima A, Yamada T, Katagiri H, Nagai R, Yamada N, Kadowaki T, and Shimano H. Glycogen shortage during fasting triggers liver-brain-adipose neurocircuitry to facilitate fat utilization. Nat Commun 4: 2316, 2013.

17. Jentjens $\mathbf{R L}$, and Jeukendrup $\mathbf{A E}$. High rates of exogenous carbohydrate oxidation from a mixture of glucose and fructose ingested during prolonged cycling exercise. Br J Nutr 93: 485-492, 2005. 
560 18. Jentjens RL, Shaw C, Birtles T, Waring RH, Harding LK, and

561 Jeukendrup AE. Oxidation of combined ingestion of glucose and sucrose during exercise. Metabolism 54: 610-618, 2005.

19. Jeukendrup AE. Carbohydrate and exercise performance: the role of multiple transportable carbohydrates. Curr Opin Clin Nutr Metab Care 13: 452-457, 2010.

20. Jeukendrup AE, Raben A, Gijsen A, Stegen JH, Brouns F, Saris WH, and Wagenmakers AJ. Glucose kinetics during prolonged exercise in highly trained human subjects: effect of glucose ingestion. J Physio/515 ( Pt 2): 579-589, 1999.

21. Jeukendrup AE, Wagenmakers AJ, Stegen JH, Gijsen AP, Brouns $\mathbf{F}$, and Saris WH. Carbohydrate ingestion can completely suppress endogenous glucose production during exercise. Am J Physiol 276: E672683, 1999.

22. Jeukendrup AE, and Wallis GA. Measurement of substrate oxidation during exercise by means of gas exchange measurements. Int J Sports Med 26 Suppl 1: S28-37, 2005.

\section{Kuipers H, Verstappen FT, Keizer HA, Geurten P, and van}

Kranenburg G. Variability of aerobic performance in the laboratory and its physiologic correlates. Int J Sports Med 6: 197-201, 1985.

24. Lecoultre V, Benoit R, Carrel G, Schutz Y, Millet GP, Tappy L, and Schneiter $\mathbf{P}$. Fructose and glucose co-ingestion during prolonged exercise increases lactate and glucose fluxes and oxidation compared with an equimolar intake of glucose. Am J Clin Nutr 92: 1071-1079, 2010.

25. Lim EL, Hollingsworth KG, Smith FE, Thelwall PE, and Taylor R. Effects of raising muscle glycogen synthesis rate on skeletal muscle ATP turnover rate in type 2 diabetes. Am J Physiol Endocrinol Metab 301: E11551162, 2011.

26. Lim EL, Hollingsworth KG, Smith FE, Thelwall PE, and Taylor R. Inhibition of lipolysis in Type 2 diabetes normalizes glucose disposal without change in muscle glycogen synthesis rates. Clin Sci 121: 169-177, 2011.

\section{Liu C, Wu J, Zhu J, Kuei C, Yu J, Shelton J, Sutton SW, Li X, Yun} SJ, Mirzadegan T, Mazur C, Kamme F, and Lovenberg TW. Lactate inhibits lipolysis in fat cells through activation of an orphan G-protein-coupled receptor, GPR81. J Biol Chem 284: 2811-2822, 2009.

28. Macauley M, Smith FE, Thelwall PE, Hollingsworth KG, and Taylor R. Diurnal variation in skeletal muscle and liver glycogen in humans with normal health and Type 2 diabetes. Clin Sci 128: 707-713, 2015.

29. Miller BF, Fattor JA, Jacobs KA, Horning MA, Navazio F, Lindinger MI, and Brooks GA. Lactate and glucose interactions during rest and exercise in men: effect of exogenous lactate infusion. J Physiol 544: 963-975, 2002.

30. Mithieux G, Misery P, Magnan C, Pillot B, Gautier-Stein A, Bernard C, Rajas F, and Zitoun C. Portal sensing of intestinal gluconeogenesis is a mechanistic link in the diminution of food intake induced by diet protein. Cell Metab 2: 321-329, 2005. 31. Naressi A, Couturier C, Castang I, de Beer R, and GraveronDemilly D. Java-based graphical user interface for MRUI, a software package for quantitation of in vivo/medical magnetic resonance spectroscopy signals. Comp Biol Med 31: 269-286, 2001. 
32. Nilsson LH, and Hultman E. Liver and muscle glycogen in man after glucose and fructose infusion. Scand J Clin Lab Invest 33: 5-10, 1974. 33. Rossmann A, Butzenlechner M, and Schmidt HL. Evidence for a nonstatistical carbon isotope distribution in natural glucose. Plant Physiol 96: 609-614, 1991.

34. Rothman DL, Shulman RG, and Shulman GI. N.m.r. studies of muscle glycogen synthesis in normal and non-insulin-dependent diabetic subjects. Biochem Soc Trans 19: 992-994, 1991.

35. Smith JW, Zachwieja JJ, Peronnet F, Passe DH, Massicotte D, Lavoie C, and Pascoe DD. Fuel selection and cycling endurance performance with ingestion of [13C]glucose: evidence for a carbohydrate dose response. J Appl Physiol 108: 1520-1529, 2010.

36. Stellingwerff T, Boon H, Gijsen AP, Stegen JH, Kuipers H, and van Loon LJ. Carbohydrate supplementation during prolonged cycling exercise spares muscle glycogen but does not affect intramyocellular lipid use. Pflugers Archiv : Eur J Physiol 454: 635-647, 2007.

37. Stevenson EJ, Thelwall PE, Thomas K, Smith F, Brand-Miller J, and Trenell MI. Dietary glycemic index influences lipid oxidation but not muscle or liver glycogen oxidation during exercise. Am J Physiol Endocrinol Metab 296: E1140-1147, 2009.

38. Tsintzas $\mathbf{K}$, and Williams $\mathbf{C}$. Human muscle glycogen metabolism during exercise. Effect of carbohydrate supplementation. Sports Med 25: 723, 1998.

39. Tsintzas K, Williams C, Constantin-Teodosiu D, Hultman E, Boobis L, Clarys $\mathbf{P}$, and Greenhaff $\mathbf{P}$. Phosphocreatine degradation in type I and type II muscle fibres during submaximal exercise in man: effect of carbohydrate ingestion. J Physio/ 537: 305-311, 2001.

40. Tsintzas OK, Williams C, Boobis L, and Greenhaff P. Carbohydrate ingestion and glycogen utilization in different muscle fibre types in man. $J$ Physiol 489 ( Pt 1): 243-250, 1995.

41. van Loon LJ, Greenhaff PL, Constantin-Teodosiu D, Saris WH, and Wagenmakers AJ. The effects of increasing exercise intensity on muscle fuel utilisation in humans. J Physiol 536: 295-304, 2001.

42. Vandenbogaerde TJ, and Hopkins WG. Effects of acute carbohydrate supplementation on endurance performance: a meta-analysis. Sports Med 41: 773-792, 2011. 43. Wallis GA, and Wittekind $\mathbf{A}$. Is there a specific role for sucrose in sports and exercise performance? Int J Sport Nutr Exerc Metab 23: 571-583, 2013. 
FIGURE LEGENDS

651 Figure 1 Ratings of perceived exertion (A) and gut discomfort (B) during $3 \mathrm{~h}$

652 of cycling with ingestion of glucose or sucrose in trained cyclists $(n=14)$. Data

653 are expressed as means $\pm 95 \% \mathrm{Cl}$. ${ }^{*} P<0.05$, significantly different between

654 GLU and SUC. GLU, glucose; SUC, sucrose.
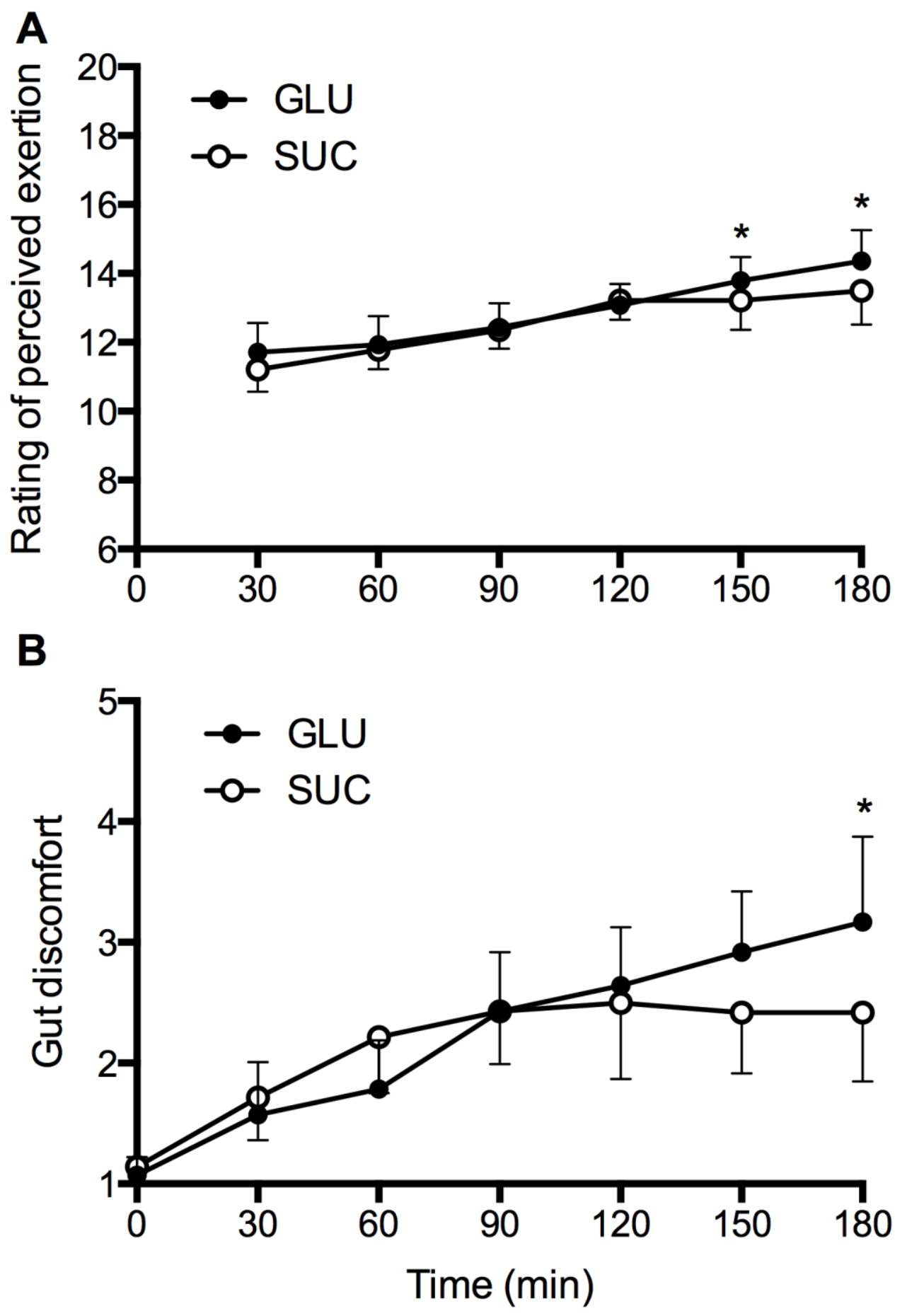
656 Figure $2 \mathrm{VO}_{2}(\mathrm{~A}), \mathrm{VCO}_{2}(\mathrm{~B})$ and respiratory exchange ratio $(\mathrm{C})$ during $3 \mathrm{~h}$ of 657 cycling with ingestion of glucose or sucrose in trained cyclists $(n=14)$. Data 658 are expressed as means $\pm 95 \% \mathrm{Cl}$. ${ }^{*} P<0.05$, significantly different between 659 GLU and SUC. GLU, glucose; SUC, sucrose; $\mathrm{VCO}_{2}$, rate of carbon dioxide 660 production; $\mathrm{VO}_{2}$, rate of oxygen consumption.

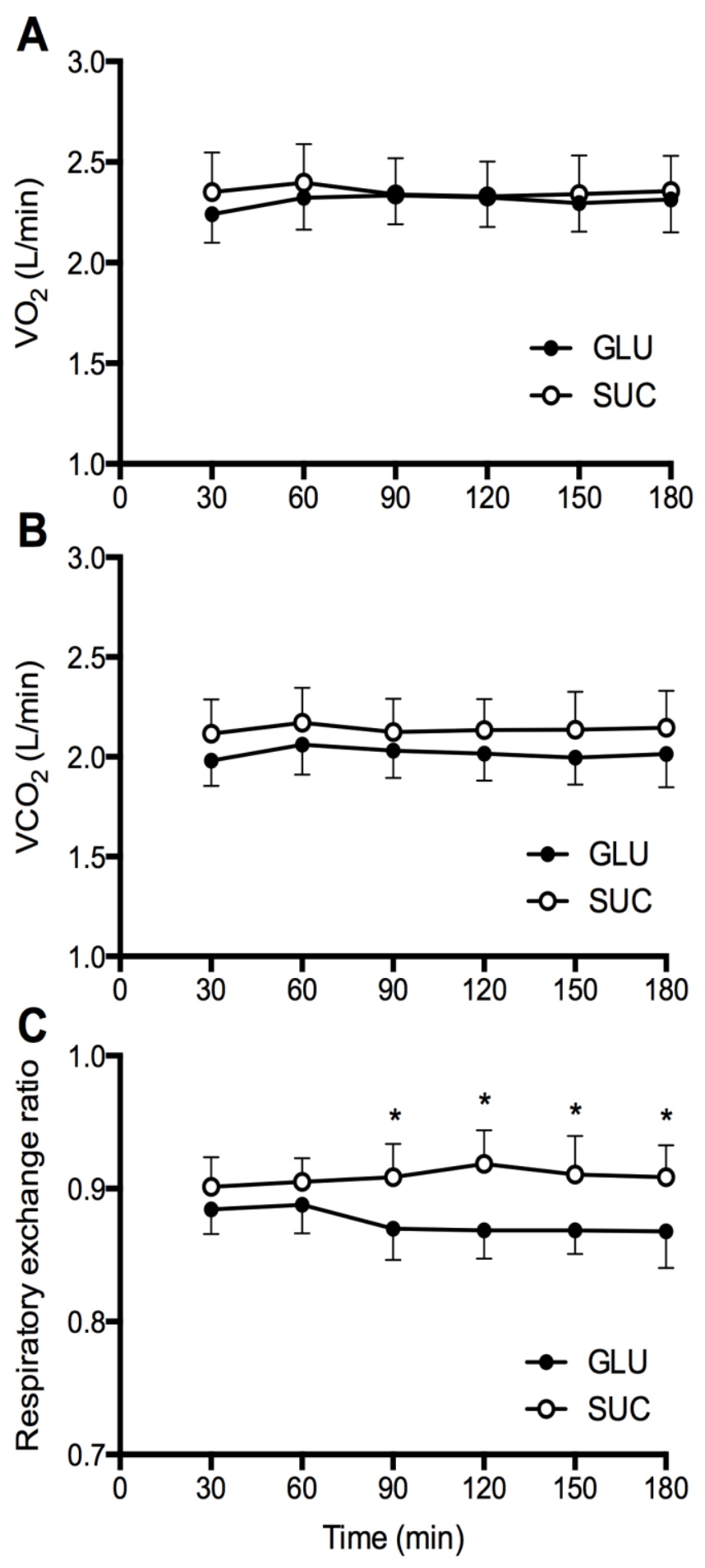


662 Figure 3 Substrate utilization during $3 \mathrm{~h}$ of cycling with ingestion of glucose or

663 sucrose in trained cyclists $(A ; n=14)$ and in the subgroup of trained cyclists

664 (B; $n=4)$. Data are expressed as means $\pm 95 \% \mathrm{Cl}$. ${ }^{*} P<0.05$, significantly

665 different from CON. CHO, carbohydrate; GLU, glucose; SUC, sucrose; CON,

666 water control.

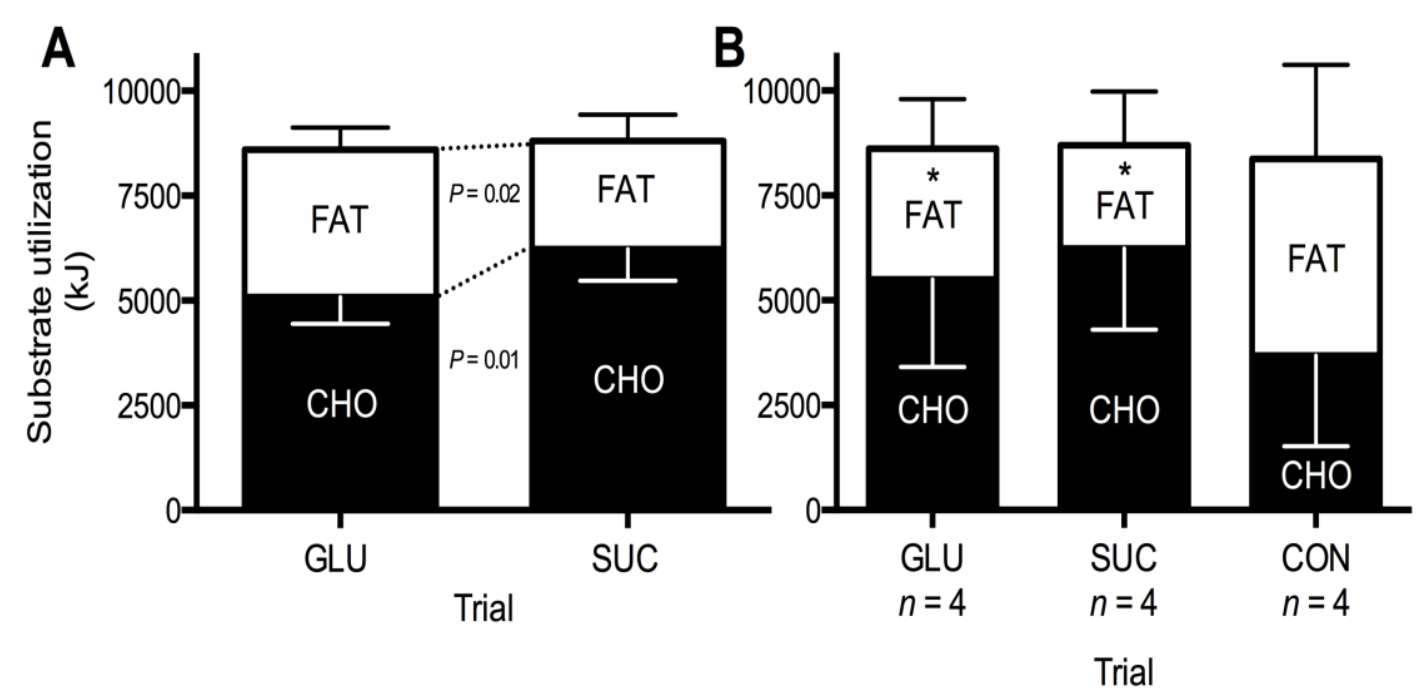

667

668 
669 Figure 4 Blood glucose (A) and lactate (B), and plasma insulin (C) and NEFA

670 (D) concentrations during $3 \mathrm{~h}$ of cycling with ingestion of glucose or sucrose in

671 trained cyclists $(n=14)$. Data are expressed as means $\pm 95 \% \mathrm{Cl}$. ${ }^{*} P<0.05$,

672 significantly different between GLU and SUC. GLU, glucose; NEFA, non-

673 esterified fatty acid; SUC, sucrose.

A
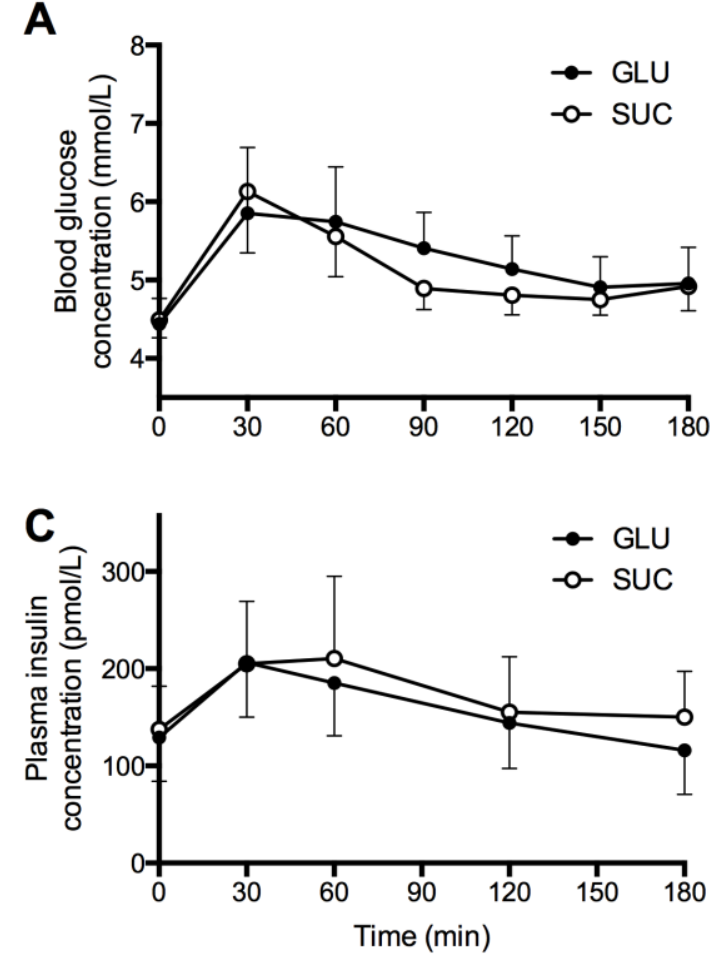

B
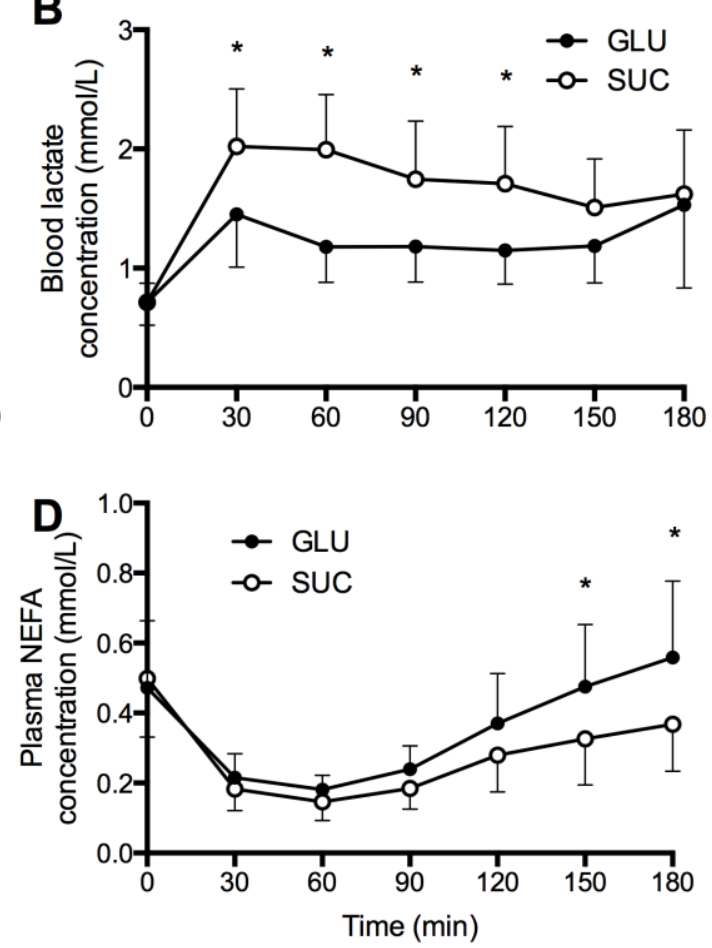

674

675 
676 Figure 5 Liver glycogen (A), muscle glycogen (C) and intramyocellular lipid

677 (E) concentrations prior to (Pre) and immediately following (Post) $3 \mathrm{~h}$ of

678 cycling with ingestion of glucose or sucrose in the full sample of trained

679 cyclists $(n=14)$, and in the subgroup of trained cyclists $(\mathrm{B}, \mathrm{D}$ and $\mathrm{F} ; n=4)$.

680 Data are expressed as means $\pm 95 \% \mathrm{Cl}$. ${ }^{*} P<0.05$, significantly different

681 when compared with pre-exercise values. GLU, glucose; SUC, sucrose; CON, 682 water control.
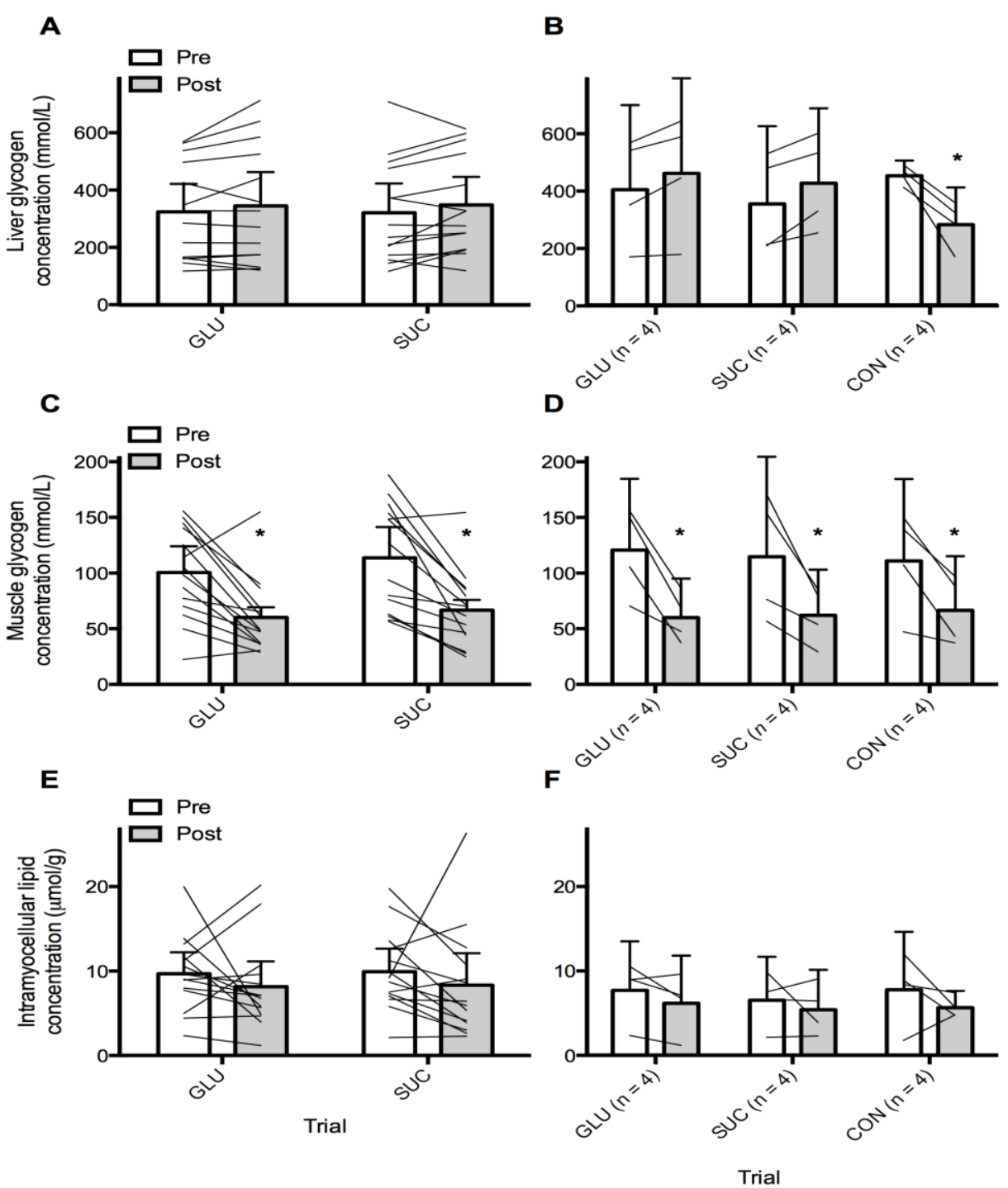
Table 1 Carbohydrate intake and physiological variables of trained cyclists 685 during $3 \mathrm{~h}$ of cycling with ingestion of glucose, sucrose or water.

\begin{tabular}{lccc}
\hline & GLU & SUC & CON \\
& $(n=14)$ & $(n=14)$ & $(n=4)$ \\
\hline Carbohydrate intake (g/min) & $1.7 \pm 0.2$ & $1.7 \pm 0.2$ & $0 \pm 0$ \\
Fluid intake (L) & $2.1 \pm 0.2$ & $2.2 \pm 0.2$ & $2.3 \pm 0.0$ \\
Power output (W) & $165 \pm 17$ & $165 \pm 17$ & $158 \pm 7$ \\
Mean heart rate (beats/min) & $145 \pm 14$ & $146 \pm 12$ & $122 \pm 8$ \\
\hline
\end{tabular}

Data are expressed as means \pm SEM. GLU, glucose; SUC, sucrose; CON,

687 water control.

688

689

690

691

692

693 
Table 2 Characteristics of trained cyclists who completed GLU, SUC and 695 CON trials.

696

697

698

699

700

701

702

703

704

705

706

707

708

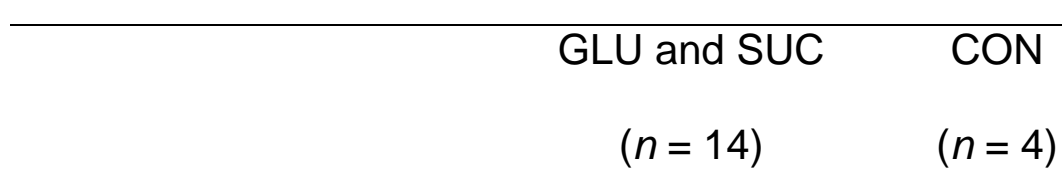

\begin{tabular}{lll}
\hline Age (y) & $25 \pm 5$ & $26 \pm 6$
\end{tabular}

Body mass $(\mathrm{kg})$

$73.1 \pm 9.3 \quad 75.3 \pm 10.7$

Height ( $m)$

$1.78 \pm 0.08$

$1.75 \pm 0.09$

$\dot{\mathrm{V}} \mathrm{O}_{2 \text { peak }}(\mathrm{mL} / \mathrm{min} / \mathrm{kg})$

$58 \pm 5$

$60 \pm 7$

$W_{\text {peak }}(\mathrm{W})$

$330 \pm 35$

$316 \pm 27$

$\operatorname{BMI}\left(\mathrm{kg} / \mathrm{m}^{2}\right)$

$23.0 \pm 1.9$

$24.5 \pm 1.8$

Systolic blood pressure

$133 \pm 11$

$129 \pm 6$

$(\mathrm{mmHg})$

Diastolic blood pressure

$74 \pm 8$

$71 \pm 8$

$(\mathrm{mmHg})$

709 Data are expressed as means \pm SD. GLU, glucose; SUC, sucrose; $\dot{\mathrm{V}}_{2 \text { peak, }}$

710 peak oxygen uptake; CON, water control; $W_{\text {peak, }}$ peak power output.

711 